\title{
Mechanistic Role of Egyptian Propolis Against Ehrlich Ascites Carcinoma and Methotrexate Limitations
}

\author{
Maha M Salem $^{* 1}$, Thoria Donia ${ }^{1}$, Ehab M M Ali ${ }^{1,2}$ and Tarek M Mohamed ${ }^{1}$ \\ ${ }^{1}$ Faculty of Science, Department of Chemistry, Biochemistry Division, Tanta University, Tanta, Egypt \\ ${ }^{2}$ Departement of Chemistry, College of Science, King Faisal University, Al-Ahsaa, Saudi Arabia
}

*Corresponding author: Maha M Salem, Faculty of Science, Department of Chemistry, Biochemistry Division, Tanta University, Tanta, Egypt

\section{ARTICLE INFO}

Received: 彗 September 21, 2021

Published: 豐 October 01, 2021

Citation: Maha M Salem, Thoria Donia, Ehab M M Ali, Tarek M Mohamed. Mechanistic Role of Egyptian Propolis Against Ehrlich Ascites Carcinoma and Methotrexate Limitations. Biomed J Sci \& Tech Res 39(1)-2021. BJSTR. MS.ID.006258.

Keywords: Cancer; Propolis; Methotrexate; Ehrlich Ascites Carcinoma

\begin{abstract}
Although several conventional anti-cancer drugs are available, most of them are toxic and intolerable after long-term use. Therefore, there has been a global increased interest to identify novel agents that can possess anti-tumor effects by it or maximize the anti-tumor effects of low doses of conventional anti-cancer drugs. Egyptian propolis is a powerful antioxidant and free radical scavenger produced by bee. The current review was designed to characterize Egyptian propolis, investigate its anticancer effect and a potential protective role against methotrexate (MTX) toxicity.
\end{abstract}

Abbreviations: EAC: Ehrlich Ascites Carcinoma; TSTA: Tumor Specific Transplantation Antigen; ALL: Acute Lymphatic Leukemia; DHFR: Dihydrofolate Reductase; PMNs: Polymorphonuclear Neutrophils; ROS: Reactive Oxygen Species; CZE: Capillary Zone Electrophoresis; INFs: Induce the Production of Interferon's; PEE: Propolis Ethanolic Extract; CAPE: Caffeic Acid Phenyl Ester

\section{Cancer and Its Incidence}

Cancer is characterized by the uncontrolled growth of abnormal cells which disrupt body tissue, metabolism. It tends to spread locally to various parts of the body. The genetic and environmental factors are crucial for cancer formation and progression. Among the environmental factors are the lifestyle of people that include tobacco, alcohol, and physical activity. Industry, microbial factors (radiation, pollution, infection) and diet are also important reasons for cancer development [1]. About 18 million cancer cases and 10 million cancer deaths were estimated in 2018. One of the most diagnosed cancers is the lung cancer that leads to death. It is followed by breast cancer, prostate cancer, colorectal cancer stomach cancer, and liver cancer for mortality. Lung cancer is the most frequent and leads to death among males, followed by prostate and colorectal cancer. Breast cancer is also the most diagnosed cancer that causes cancer death followed by colorectal and lung cancer. Cervical cancer ranks the fourth for both incidence and mortality.

In Egypt, the commonest sites of cancer in Egyptian males are liver, bladder, non-Hodgkin's lymphoma, lung and prostate. These sites represent $60.2 \%$ of all cancer in males. The commonest sites in Egyptian females are breast, liver, non-Hodgkin's lymphoma, colorectal and ovary. These represent $61 \%$ of cancer in females as in Figure 1. 


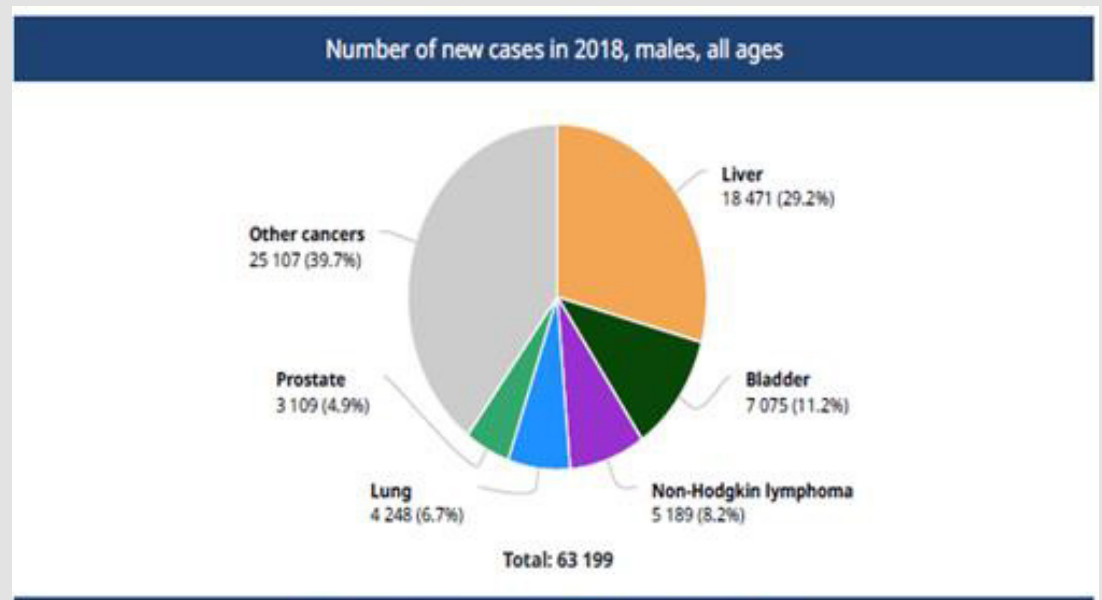

Number of new cases in 2018, females, all ages

Figure 1: Incidence of cancer in Egypt.

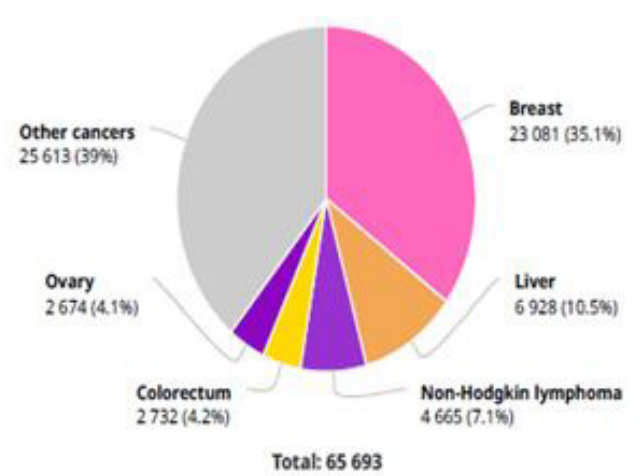

\section{Ehrlich Ascites Carcinoma (EAC)}

Experimental tumors are important for modeling, where EAC is one of the commonest. Initially it appears as a spontaneous breast cancer in the female mouse. It is used as an experimental tumor by transplanting tumor tissues subcutaneously from mouse to another [2,3]. The liquid form in the peritoneum of the mouse and called it as "Ehrlich ascites carcinoma" owing to the ascites liquid with the carcinoma cells. EAC is an undifferentiated carcinoma. It is originally hyperdiploid that has high transplantable capability, rapid proliferation and shorter life span. It has 100\% malignancy and has no tumor specific transplantation antigen (TSTA). EAC likes human tumors. The tumors are most sensitive to chemotherapy because they are undifferentiated and have rapid growth rate. The rate of proliferating of EAC cells was characterized in four phases. The phases are

(1) A logarithmic phase for four or five days, after 107 tumor cells transplantation intraperitoneal (i.p.),

(2) A plateau phase where the number of cells stayed constant on the $5^{\text {th }}$ to $13^{\text {th }}$ day,
(3) A transitory proliferating phase on the $13^{\text {th }}$ to $15^{\text {th }}$ day,

(4) A second plateau phase on the $15^{\text {th }}$ to $18^{\text {th }}$ day [4].

In general, the EAC model could be applied owing to its assessment of the cancer biology. Also, the cellular and molecular mechanisms of novel anti-proliferation, anti-angiogenic, antimetastatic effects of compounds against cancer could be assessment.

\section{Cancer Treatment}

The treatment of cancer is a multidisciplinary therapy that consists of radiotherapy, surgery, chemotherapy and immunotherapy [5]. The treatment depends on the cancer type, its state of advancement and its location. The first treatment is surgery. It is useful in removing of solid tumors. It may be necessary for the early stage of cancers and benign tumors. It may leave residual cancer cells and has undesirable side effect. It changes the rate of growth of the remained cancer cells via triggering a faster metastatic process. The multimodal therapy such as immunotherapy, radiotherapy, chemotherapy and other forms of treatments come after surgery in order to provide a good chance to kill the metastatic cancer cells or keeping them in the remission state [6]. The radiotherapy may 
cure cancer in different sites of the body. This technique destroys cancer cells by using high-energy X-rays targeted directly to the tumor. During the radiotherapy treatment, the water molecules in the body form what is called free radicals. The free radicals destroy the cell's DNA by oxidation while preventing its replication.

They kill the cancer cells which rapidly divide. Location, type, stage of cancer, person's age and general health are all factors affect the radiotherapy. Radiotherapy may be the only treatment with chemotherapy before surgery to shrink the tumor. It is used after surgery to kill off any remaining cancer cells and to ease symptoms such as bleeding. The common side effects of radiotherapy are the killing of dividing healthy cells near by the cancer cells including the fatigue and the skin itchiness and color changes [7].

\section{Chemotherapy}

Chemotherapy is considered as one of cancer treatment that involves the use of therapeutic agents which have direct tumorkilling properties. It is the most effective for cancers that divide rapidly and have good blood supply. The treatment by chemotherapy cures maintains long term remission (free of disease) increases the effectiveness of surgery or radiotherapy and helps to control pain and other symptoms. The effective drugs in treating cancer interfere with the cancer cells activity. This takes place by going directly into the sabotage of a specific phase of cell development or by sending messages that confuse the cells to destroy themselves. It is well known that not all drugs are effective against all cancers but various groups of drugs act in different way [8]. Nowadays, the antitumor chemotherapy is very limited although there are many advances in the research and development of different cancer drugs [9]. A major problem of chemotherapy drugs is that the drugs are not specifically selective for neoplastic cells but can eliminate the normal healthy cells too particularly those often divide. If multiple cell lines have destroyed the organ toxicity occurs. Patients with cancer receiving chemotherapy are commonly suffered from anemia, proneness to infections and hair loss. Examples for different chemotherapies are 5-flurouracil, cisplatin and methotrexate (MTX) and their side effects.

\section{Methotrexate}

Methotrexate, (2,4-diamino-N10-methyl propyl glutamic acid) is an analog of folic acid in which the groups bonded to the C4 carbon and $\mathrm{N} 10$ hydrogen are $\mathrm{NH}_{2}$ and $\mathrm{CH}_{3}$. The structure of the molecule consists of three parts as in Figure 2. MTX has received intensive studies and proved effective therapeutics agents. It treats many solid tumors, autoimmune diseases, and hematologic malignancies [10]. It is a folate antimetabolite with antineoplastic and antirheumatic properties which play a great role in treatment of breast cancer, osteogenic sarcoma, lung cancer, choriocarcinoma, bladder carcinoma, acute lymphatic leukemia (ALL), brain medulloblastoma, primary lymphoma psoriasis, chronic myeloid leukemia and rheumatoid arthritis [11]. The mechanism by which the MTX acts as a cancer chemotherapeutic agent is the inhibition of the dihydrofolate reductase (DHFR) with high affinity giving rise to a depletion of tetrahydrofolates that are needed for the synthesis of both the purines and thymidine. Thus, the synthesis of RNA, DNA and other metabolic reactions is interrupted by MTX. It interferes with mitotic cell division as described in Figure 3 [12].

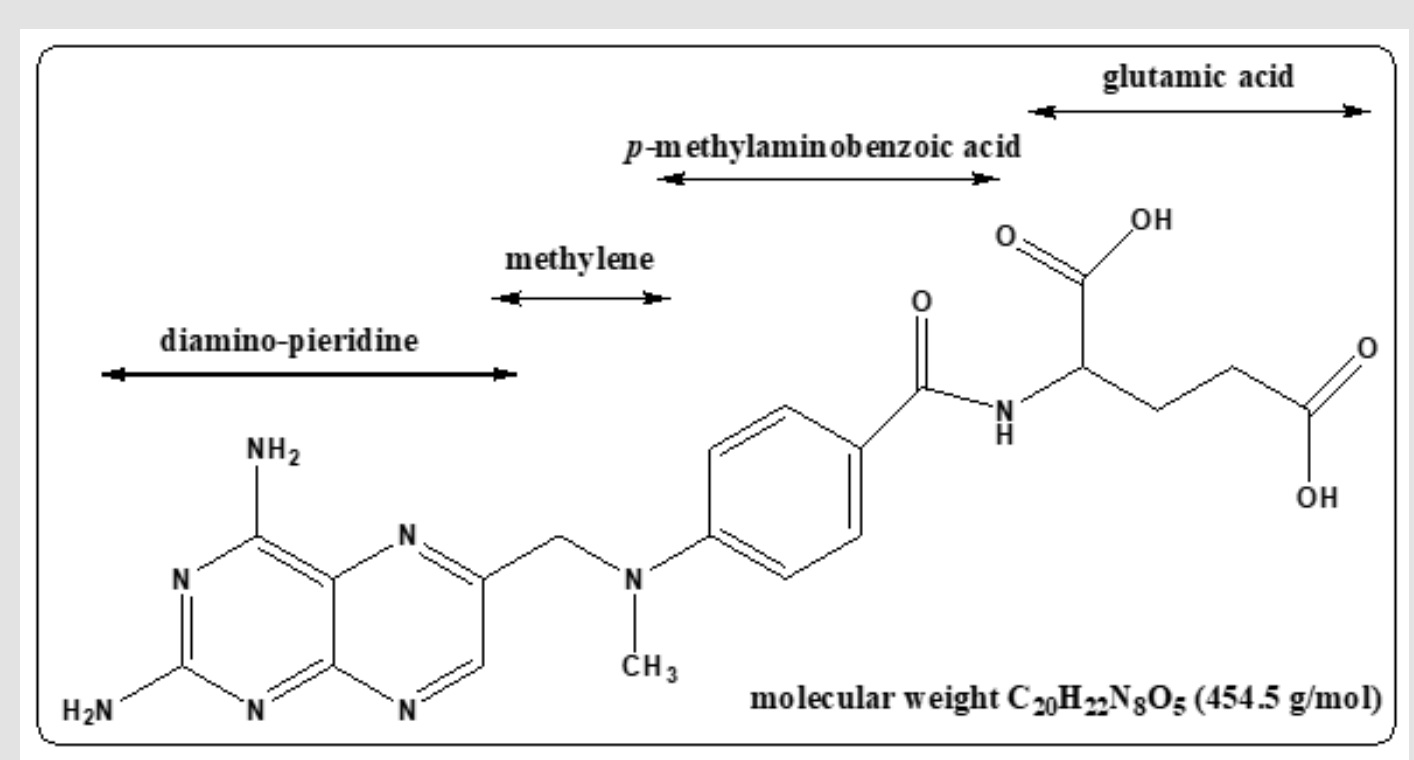

Figure 2: Chemical structure of methotrexate. 


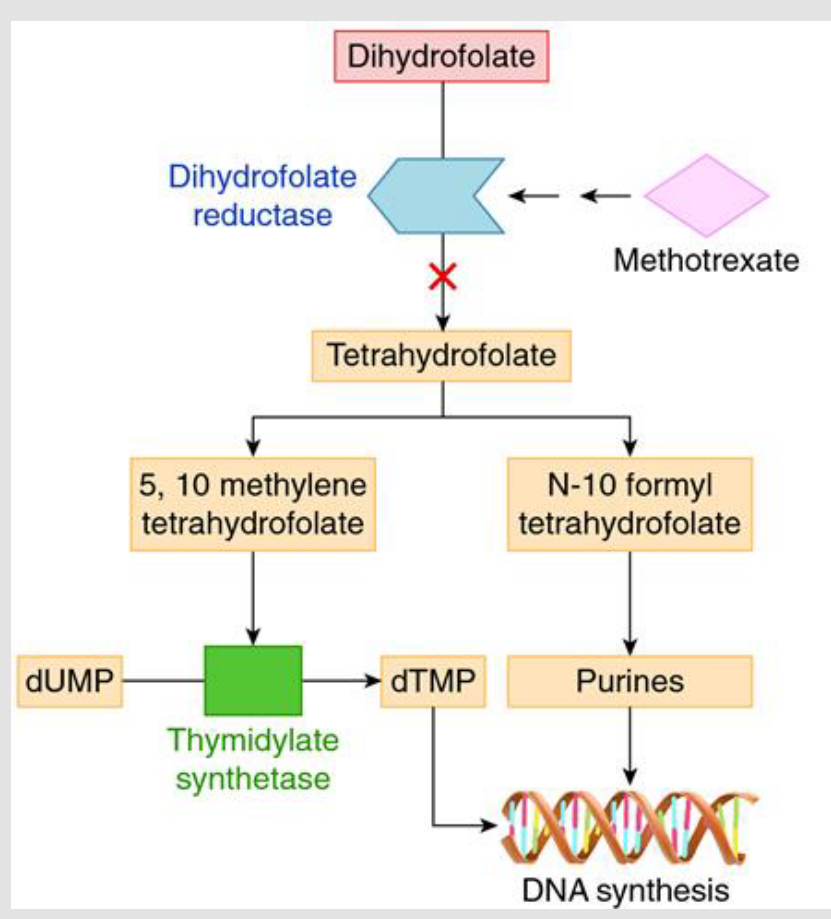

Figure 3: Mode of action of MTX in cancer.

The dihydrofolate reductase enzyme is the initial cellular target of MTX and other antifolates. It catalyzes the reduction of folate and 7,8 dihydrofolate to 5,6,7,8 tetrahydrofolate. Primary MTX enters the cell by an active carrier transport mechanism and shared by the reduced folates and mediated by the reduced folate carrier (RFC) [13]. MTX is modified inside the cell and retained in it. This is established by the addition of glutamate residues (up to 5) catalyzed by the folylpolyglutamate synthetase enzyme $[14,15]$. MTX and its polyglutamylated forms are tightly binding inhibitors for DHFR. They interfere with pyrimidine and thymidylate biosynthesis. MTX polyglutamates together with dihydrofolate polyglutamates are inhibitors for enzymes involved in the purine biosynthesis including the aminoimidazole carboxamide ribonucleotide transformylase and phosphoribosylglycinamide transformylase. The enzymatic removal of glutamyl groups from the polyglutamylated forms of folates and MTX is efficiently catalyzed by gamma glutamyl hydrolase $[16,17]$.

The life threatening may be due to the side effect of high dose of MTX (MTX-HD). However the various doses of oral MTX are variable because of the inter-individual variability of gastrointestinal absorption of MTX. Bone marrow, gastrointestinal mucosa and hair are vulnerable to the effect of MTX. Their high rate of cellular turnover and because the MTX concentration is inversely proportional to renal clearance, the renal toxicity is frequent with MTX-HD [18]. MTX-HD is normally used as a cytotoxic chemotherapeutic agent in many malignancies treatment.
This treatment is acute lymphoblastic leukaemia and the treatment of various inflammatory diseases treatment [19]. The efficiency of this agent is limited by its toxicity that causes severe side effects and leads to liver cirrhosis, liver fibrosis, hypertrophy of the hepatocytes, hepatocellular necrosis, hepatitis, and death. In general, MTX toxicity has severe side effects on the haematopoietic system as well as liver enzymes [20]. MTX also increases the amount of $\mathrm{H}_{2} \mathrm{O}_{2}$ and free radicals generated by the stimulated polymorphonuclear neutrophils (PMNs). PMNs lead to toxicity and consequently increase the cellular damage rate.

MTX interferes with the homocysteine metabolism via decreasing the levels of 5-methyltetrahydrofolate, homocysteine levels and S-adenosylmethionine (SAM) [21]. In addition, MTX leads to methionine synthesis and reduction in antioxidant enzymes which are catalase, superoxide dismutase, glutathione peroxidase and SAM (SAM acts as an antioxidant) in cerebrospinal fluid of patients on MTX treatment [21]. The deficiency of SAM caused by MTX could be a reason for increasing the reactive oxygen species (ROS). Administration of SAM also caused lipid peroxidation inhibition in a rat model [22]. The undesirable side effects of antitumor drugs could be overcome with compounds able to discriminate the tumor cells from normal proliferative cells. The resistance can be minimized using modality approach combined with different complementary mechanism of action. At this stage, the use of natural sources is belived to have a great value for cancer control and programs destruction [23]. 
Natural products are rich with chemical compounds having antitumor and cytotoxic activities due to their enormous propensity. This propensity synthesizes a various structural diverse bioactive compounds [24]. Natural products have made significant achievements over $60 \%$ of the clinical use of anti-cancer drugs originated from natural products such as plants, marine organisms and bee products [25]. Antioxidant-rich foods are used to assess the human body to reduce the oxidative damage caused by free radicals [26]. There are many synthetic antioxidants used in the pharmaceutical and food industry has toxic and mutagenic effects [27]. The isolation and progressing of natural antioxidants such as polyphenols and flavonoids have attracted the researchers interest everywhere [28].

\section{Propolis}

Propolis is a bee product containing resins and other materials that collected by certain species of bees from buds and exudates of plants [29]. This product is also known as bee glue. It is usually sticky in nature and some are dry and gel-like in texture. Bees form the propolis by mixing their own waxes with the resins that previously collected. Certain types of bee use the propolis as glue material for building their hive while some kind of bees like Trigona sp. cover the whole hive with a mass of the propolis [30]. Bees synthesize the propolis in order to protect the bee community.
The hive covered with propolis is protected from any possible enemies. It also keeps the inner temperature of the hive at around $35{ }^{\circ} \mathrm{C}$. Propolis mixed with the bee hive hardens the cell walls and makes it stronger against any physical stress. Some bee's varieties cover the carcasses of intruders killed in the hive for the attainment of internal aseptic environment. Propolis can defensed the bees against infections, bacteria and fungi [31,32].

\section{Chemical Constituents of Propolis}

Propolis is usually creamy to dark brown in color. Some varieties are green and red. The contents of propolis vary according to the environment of the bees and depend initially on the plants around it $[32,33]$. The compounds present in the propolis are also dependent on the substances that secreted by different plants. Some of these substances are lipophilic materials on the leaves, gums and lattices aside from the resin [33]. Propolis contains esters of phenolic acid (58\%), bees wax (24\%), flavonoid aglycones $(6 \%)$, triterpenes $(0.5 \%)$ and lipids and wax $(8 \%)$. It also contains minerals and micronutrients such as zinc, manganese, copper and pollen [34]. The buds of black poplar trees in some reigons (Populus nigra) are the main source of propolis that contains high amount of phenolic acids, flavonoid aglycones (flavones and flavonones) and esters [33].

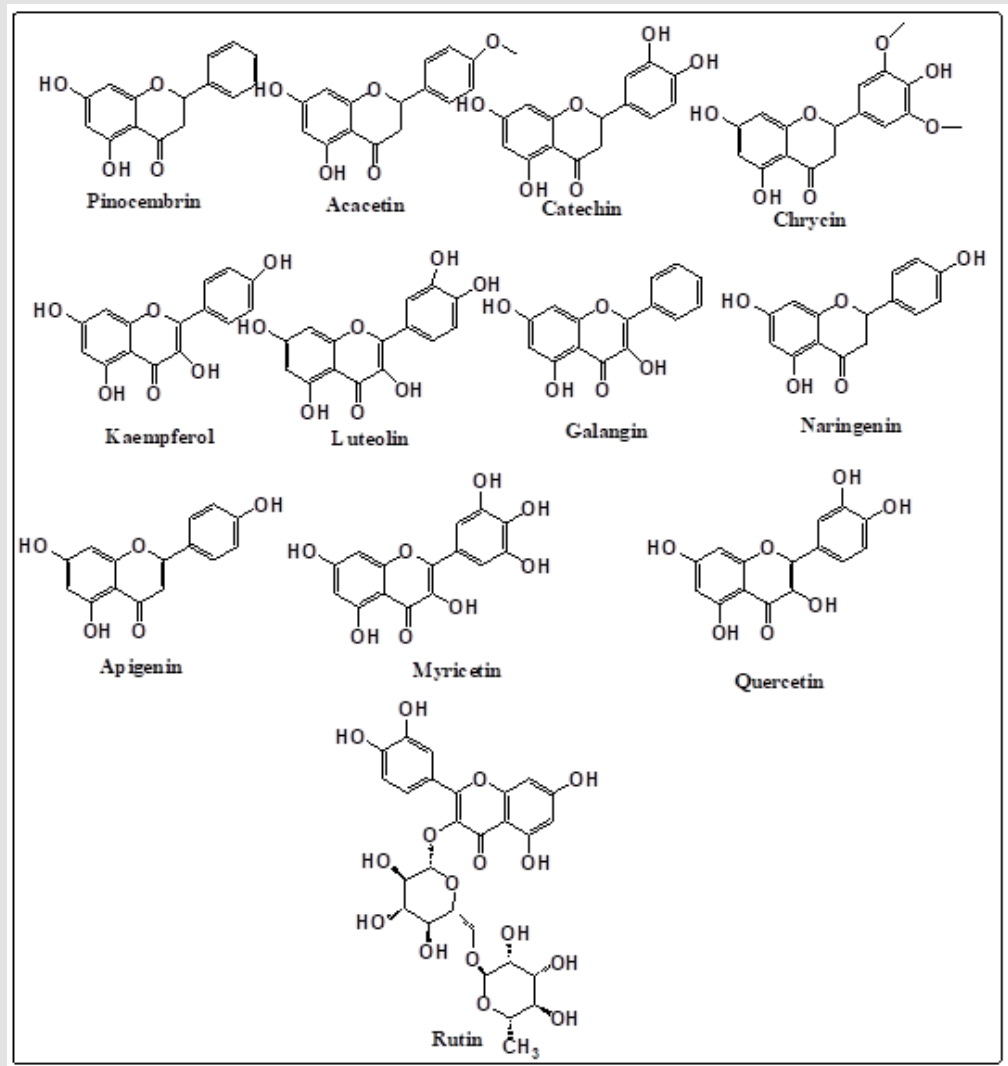

Figure 4: Major flavonoids found in propolis [35]. 
Capillary zone electrophoresis (CZE) technique is normally used for the determination of Twelve different flavonoids as acacetin, pinocembrin, rutin, chrysin, catechin, naringenin, luteolin, kaempferol, galangin, apigenin, myricetin, and quercetin. Two phenolic acids, cinnamic acid and caffeic acid and one stilbene derivative, resveratrol in propolis extracts as shown in Figures 4 \& 5 [35]. Biological activity and medicinal use of Propolis

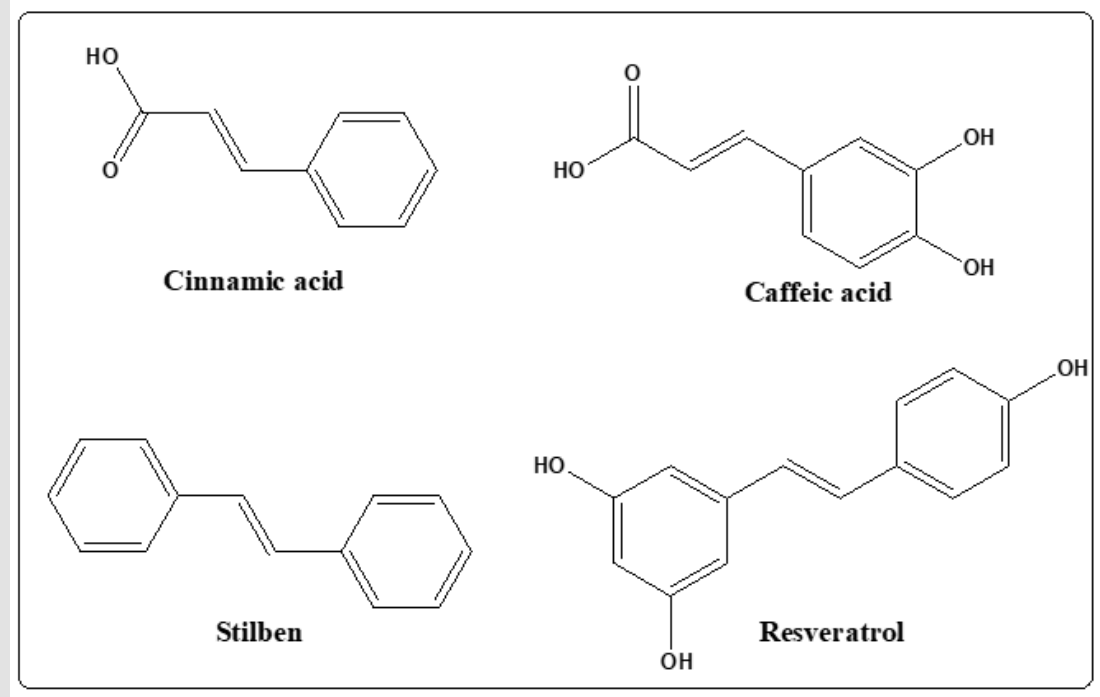

Figure 5: Major phenolics and their derivatives found in propolis[35].

\section{Antimicrobial Properties}

\section{Antiviral Activity}

Flavonoids of propolis induce the production of interferon's (INFs). Interferon's have several antiviral effects. These effects are strengthening of cell membrane and induction of nucleases which destroy the viral genome and the modification of the initiation factor phosphorylation pattern Eukaryotic. This factors affects the transduction of proteins and stops all their biosynthesis including that of viruses [36]. Isopentyl ferulated isolated from propolis was found to inhibit greatly the infectious activity of influenza virus A1 Honey Kong $\left(\mathrm{H}_{3} \mathrm{~N}_{2}\right)$ in vitro [37]. Administration of aqueous extract of Propolis decreases the mortality and increases the mean survival length in mice infection with influenza virus A/PR8/ 34 (HONI) [38]. Melliferone, moronic acid, and betulonic acid and four known aromatic compounds were successfully isolated from Brazilian Propolis and tested for anti-HIV activity in H9 lymphocytes. It was found that moronic acid has significant anti-HIV activity [39].

\section{Antibacterial Capacity}

The antibacterial activity of propolis against the gram-positive bacteria is due to the presence of aromatic acids, flavonoids, esters, flavone, flavonol, volatile fractions of phenols, caffeic acid and its esters, cinnamic acid, terpenoids, and chrysin that are present in propolis resins. These bioactive compounds can further contribute to antibacterial activity through a mechanism based on two parts, which described in Figure 6. It is known that, propolis represses the bacterial movement and enzyme activity. It exhibits bacteriostatic action towards different bacterial genera. It can also be bactericidal with high concentrations and is able to affect cytoplasmic membrane. The effect of propolis ethanolic extract (PEE) on the physiology of Bacillus subtilis, Escherichia coli, and Rhodobacter sphaeroides, was investigated [40]. H. pylori, is an important factor for gastrointestinal illnesses. This bacterium has the enzyme of peptide deformylase which catalyses the elimination of formyl group from the $\mathrm{N}$-terminus of polypeptide chains. As the activity of this enzyme is fundamental for H. pylori existence, it is viewed as a promising helpful medication target. Caffeic acid phenyl ester (CAPE) is a competitive inhibitor of peptide deformylase.

Propolis combination with synthetic antibiotics allows dose reduction of the selected antibiotics and potentiates their effect. Italian PEE greatly increases the effect of gentamycin, ampicillin and streptomycin. It also moderates the action of vancomycin, chloramphenicol and ceftriaxone. No effect was observed when the PEE was used simultaneously with erythromycin. Furthermore, the PEE which comes from Australian bee suppresses the s. aureus growth although it has a low activity towards $p$. aeruginosa. The synergism among Bulgarian, Brazilian propolis and the antibiotics (ciprofloxacin and norfloxacin) that dealing with DNA and the metabolism in salmonella typhi was investigated. 


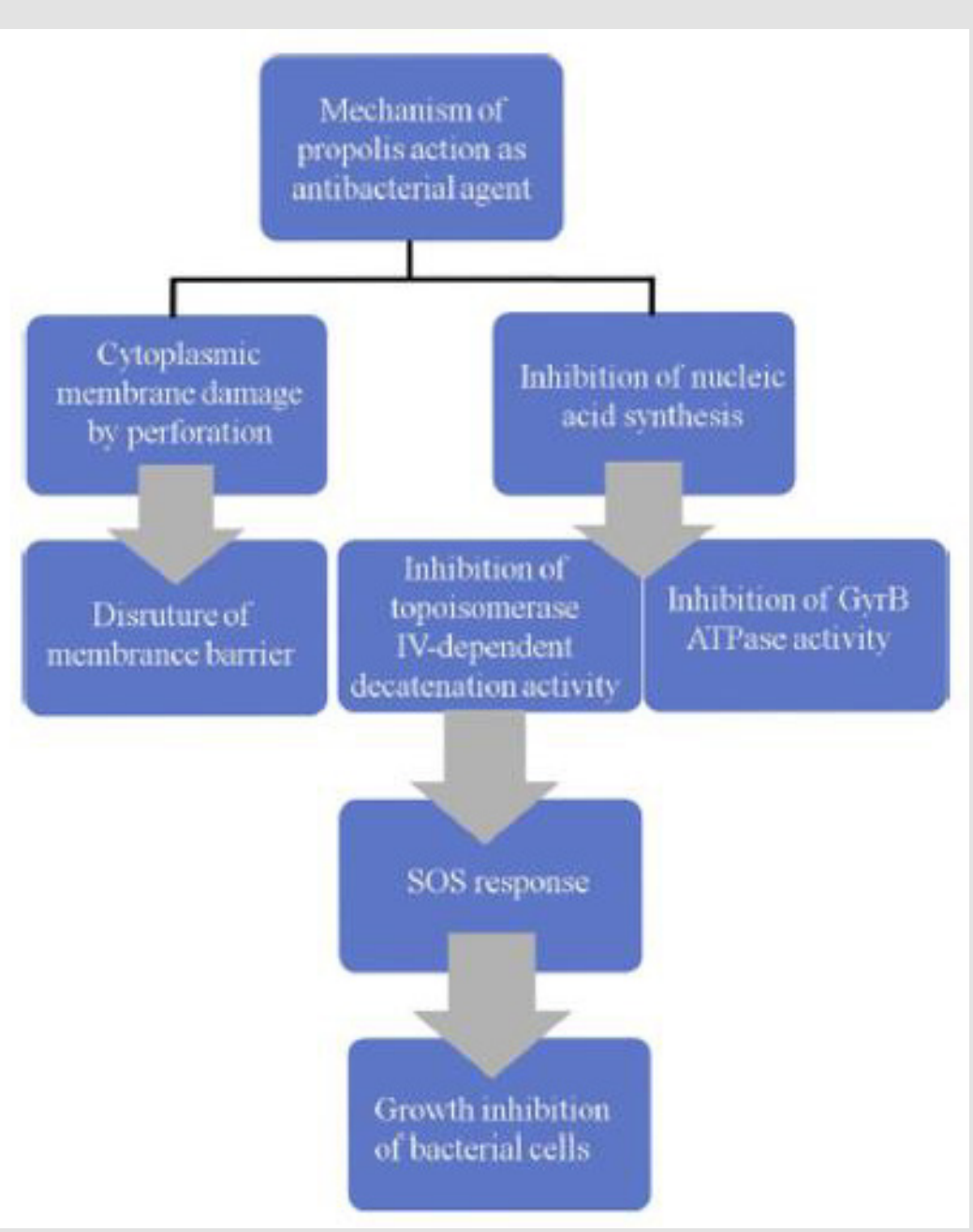

Figure 6: The mechanism of propolis as anti-bacterial agent.

\section{Anti-Fungal Activity}

The antifungal activity is a function of the chemical variation of propolis [41]. A Poland PEE sample showed high fungicidal activity towards C. albicans, C. krusei and C. glabrata. French Propolis extracts were effective against $C$. glabrata and $C$. albicans but less effective towards the A. fumigates. Brazilian PEE proved activity against different Candida strains (C. guilliermondii, C. albicans, C. krusei, and, C. tropicalis [42]. Red and green Brazilian propolis exhibits reasonable activity against various fungal species of Trichophyton. The Argentina propolis microparticles (PMs) and PEE have a good antifungal activity towards clinical yeast isolates, C. albicans and non-C. albicans. The action of different propolis extracts (PEE and propolis water extract (PWE)) as Fungicide was studied against three $C$. albicans morphotypes. It was shown that the PEE is the most effective.

\section{Antiprotozoal and Antiparastic Activity}

The ethanolic and dimethyl-sulphoxide extracts of propolis, were active against Trypanosoma cruzi [43].

\section{Antioxidant and Anti-Inflammatory Activity}

The mediators such as vasoactive amines, eicosanoids, platelet aggregation factors, cytokines, kinins and free oxygen radicals are released through injured tissue during the inflammation process. The cytokines which are released from the active macrophages lead to vessel dilatation. During this stage, the phospholiases, cyclooxygenase (COX) and lipoxygenase (LOX) are activated by the phospholipids in cytoplasmic membrane. The activation of these enzymes affects the eicosanoid, arachidonic acid metabolism and generates the main inflammatory mediators. In addition, the reactive oxygen species (ROS) produced during the inflammatory process attacks the cellular components, thus destruct lipids, proteins, and DNA [44]. Also, ROS catalyzes NF-kB translocation in the nucleus and causes transcription of cyclooxygenase- 2 (COX-2), cytokines, nitric oxide synthase (NOS), phospholipase A2, superoxide dismutase. Therefore, it leads to the damage of the tissue. The anti-inflammatory activity of both the flavonoids and phenolic acids that found in the propolis comes from their antioxidative properties. 
These bioactive compounds inhibit the activity of lipoxygenase, cyclooxygenase, NADPH-oxidase, tyrosine-protein kinase, ornithine decarboxylase, myeloperoxidase, decrease the levels of prostaglandins (PGE2) and leukotrienes [45]. Propolis overcomes the phosphorylation of inhibitor of $\kappa \mathrm{B}$ binding protein $(\mathrm{I} \kappa \mathrm{B} \alpha$ ) and activator protein-1 (AP-1). Propolis is also capable to block the NF$\mathrm{KB}$ activation. The mechanism of propolis protective effect during the oxidative stress is discribed in Figure 7. Flavonoids and phenolic acids can be characterized by their strong antioxidant activity. This activity is related to the chemical structure of these compounds that can inhibit the activity of xanthine oxidase, ascorbic acid oxidase, protein kinase $\mathrm{C}$, cyclooxygenase, cAMP phosphodiesterase, lipoxygenase and, $\mathrm{Na}+\mathrm{K}+\mathrm{ATPase}$. These forbid the generation of ROS through scavenging, disturbing the reactions that result in lipid peroxidation, chelating metal ions, and potentiating the action of other antioxidants.

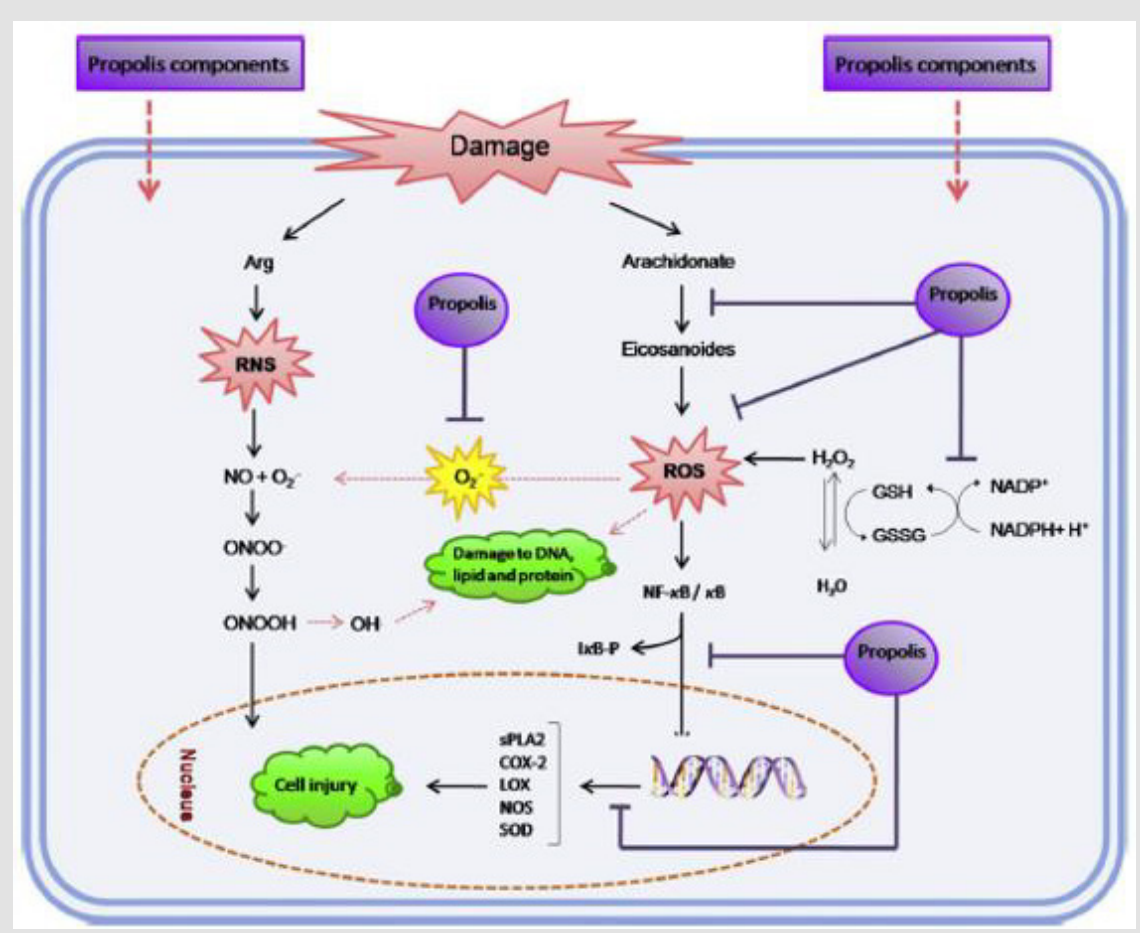

Figure 7: Signal transduction pathways.

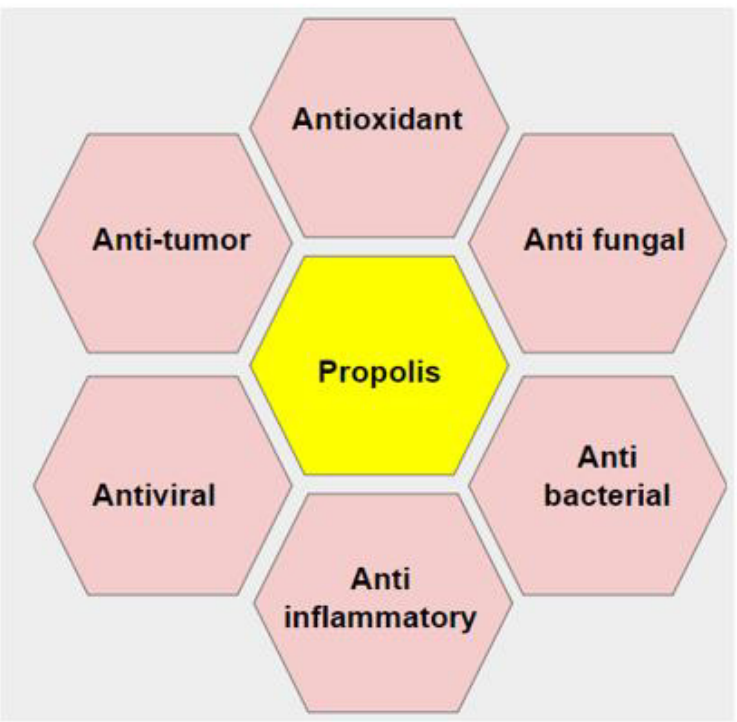

Figure 8: Major biological activities of Propolis. 
In Cuban propolis nemorosone is the most abundant compound that shows a good antioxidant capacity as reported by Cuesta-Rubio et al. Kangaroo island propolis ethyl acetate extract is rich with stilbenes that have a powerful antioxidant activity. The propolis of Anhui, China shows powerful scavenging activity due to the presence of caffeic acid and caffeate derivatives. The methanolic extracts of Algerian propolis were found to contain large amounts of flavanones, caffeic acid esters, galangin and kaempferol. They possess powerful scavenging action. The Romanian PEE decreased the concentration of malondialdehyde (MDA) and increased the activity of glutathione peroxidase. Turkish PEE has a good antioxidant activity that increases the catalase (CAT) activity and decreases the MDA levels. The compounds isolated from propolis have also revealed anti-inflammatory activity. Major flavonoids as galangin, chrysin and quercetin have reduced the PGE2 levels. This action occurred by reduction of COX and lipoxygenase expression. The quercetin, kaempferol, genistein, and daidzein inhibits activation of STAT-1 (signal transducer and activator of transcription 1) and NF-KB (nuclear factor kappa-light-chain-enhancer of activated $B$ cells) that are important transcription factors for inducible NO synthase [46] (Figure 8). Caffeic acid inhibits the arachidonic acid production as well as COX-1 and -2 activities and many oxidases such as myeloperoxidase, lipoxygenase, ornithine decarboxylase and tyrosine kinase. The artepillin $\mathrm{C}$ found in Brazilian propolis inhibits the production of PGE2 [44].

\section{Anti-Proliferative Activity}

Propolis possesses an antitumor activity in animal models and cell cultures. This activity result from the propolis ability to inhibit the DNA synthesis in tumor cells, capacity to induce apoptosis and the ability in activating the macrophages to give factors capable of regulating the function of B, T and NK cells. The flavonoids of propolis play a protective role towards the toxicity of the chemotherapeutic agents and radiation in mice. They are promising to have similar protection effect in humans. Combination with an adjuvant antioxidant therapy can increase the effectiveness of chemotherapy via ameliorating the side effect on leukocytes, kidneys and liver and therefore enable the dose escalation. Aqueous extracts from Croatian and Brazilian propolis inhibit the growth of human cervical carcinoma. The chinese hamster lung fibroblast lines, decreased the number of lung tumor nodules in mice [47]. On the other hand, water extract of Japanese propolis inhibited murine S-180 sarcoma cells and the growth of transplanted tumors in mice [48]. Ethanolic extract of Brazilian propolis prevents colon cancer development in rats induced by 1,2-dimethylhydrazine (DMH) [49], reduce human prostate cell proliferation [50]and the growth rate of colon cancer lines as $\mathrm{CaCo}_{2}$, HT-29, HCT116, and SW480. The activity of the anti-colon cancer of Chinese propolis ethanolic extract was reported by Karapetsas et al.

Methanolic extract of Brazilian propolis has cytotoxic effect against human pancreatic cancer line PANC-1 [51].
Chrysin flavonoid constituent of temperate Propolis was found to disturb the cell cycle progression and cancerous cell division. It also decreases in expression of telomerase reverse transcriptase in human [52]. Beside chrysin the caffeic acid and quercetin have exhibited powerful cytotoxic effect on leukaemia cell lines [53]. Chrysin reduces the size and the number of preneoplasmic hepatic nodules that induced by diethylnitrosamine in rats. It also reduced the expression of COX-2, NF-kB [54]. A large number of flavonoids have antineoplastic activity. A flavanol from Mexican propolis showed action towards the A549 lung cancer. The HT1080 fibrosarcoma cell line is stronger than 5-fluorouracil. Some terpenes from propolis have proved anticancer potential effect. Two cycloartanes from Burmese Propolis demonstrated strong cytotoxicity against A549, HT-1080, PANC-1 and HeLa. Manool and diterpene of the Greek propolis evidenced specific antiproliferative activity against the colon HT-29 cancer line [55].

Most of studied compounds of propolis against cancer are CAPE. Various studies have illustrated that CAPE has cytostatic and cytotoxic action against several cancer cell lines in both animal and human [56]. CAPE has specific antioxidant activity. It prevents the carcinogenesis by oxidative stress. It has been suggested to be template for the design of anticancer drug within this area $[57,58]$. Various cinnamic acid derivatives from Brazilian propolis investigated for anticancer activity included artepillin C, drupanin and baccharin [59]. These compounds showed cytostatic effect at low concentration on human gastric, colon cancer and leukemia cell lines [59]. In addition, artepillin C has wide apoptotic antineoplastic activity on human cancer cell lines and in vivo as reported by Kimoto et al.; Bhargava et al; Ferreira and Negri.

\section{Other Important Activities of Propolis}

Many investigations revealed useful results in diabetes with propolis. Application on encapsulation of propolis in type-2 diabetes mellitus has been reported to minimize the level of glucose in blood during fasting and also to increase the endogenous activity of insulin [60]. CAPE has also been proposed as an anti-diabetic agent. It greatly stimulates glucose uptake in cultured skeletal muscle cells [61]. Green Propolis of Brazil possesses anti-ulcer action in stomach and diabetic ulcers. It increases the epithelialization rates and reduces the ingress of pro-inflammatory neutrophils and macrophages [44,62]. Propolis of Australia has protective activity against sunburn and skin cancers. It reduces the cutaneous inflammation, immunosuppression and lipid peroxidation induced by UV exposure [63]. Other skin protection activity has been found by CAPE in several melanoma cell lines [64].

\section{References}

1. Ruiz RB, PS Hernández (2014) Diet and cancer: risk factors and epidemiological evidence. Maturitas 77(3): 202-208.

2. Mahadimane PV, V Vasudev (2013) Effect of methyl methane sulfonate on Ehrlich Ascites Carcinoma cells: dose effect relationships. International Journal of Lifescience and Pharma Research 3: 22-31. 
3. Ikitimur-Armutak EI, M Gurtekin (2014) Ehrlich ascites tümörü ile balb-c farelerde olușturulmuș solid tümör modelinde curcuminin apoptoz üzerine etkileri. İstanbul Üniversitesi Veteriner Fakültesi Dergisi 40(2): 183-190

4. Szikla K (1981) variations of thymidine kinase-activity and dna content in ehrlich and 11210 ascites tumor-cells during tumor-growth. Cancer biochemistry biophysics 5(4): 259.

5. Jönsson B, G Karlsson (1990) Economic evaluation of cancer treatments. Drug Delivery in Cancer Treatment III Springer, pp. 63-84

6. Care CTFoPH (2011) Recommendations on screening for breast cancer in average-risk women aged 40-74 years. Canadian Medical Association Journal 183(17): 1991-2001.

7. Sathornsumetee S, JN Rich (2007) Antiangiogenic therapy in malignant glioma: promise and challenge. Current pharmaceutical design 13(35): 3545-3558.

8. Khin YW (2005) Thesis: paclitaxel loaded nanoparticles of biodegradable polymers for cancer chemotherapy.

9. Alapati V, MN Noolvi, SN Manjula, KJ Pallavi, HM Patel, et al. (2012) In vivo anti-tumour activity of novel Quinazoline derivatives. Eur Rev Med Pharmacol Sci 16(13): 1753-1764.

10. Purcell WT, DS Ettinger (2003) Novel antifolate drugs. Current oncology reports 5(2): 114-125.

11. Grim J, Chládek J, Martínková J (2003) Pharmacokinetics and pharmacodynamics of methotrexate in non-neoplastic diseases. Clinical pharmacokinetics 42(2):139-151.

12. Genestier L, R Paillot, L Quemeneur, K Izeradjene, JP Revillard (2000) Mechanisms of action of methotrexate. Immunopharmacology 47(2): 247-257.

13. Goldman ID, LH Matherly (1985) The cellular pharmacology of methotrexate. Pharmacology \& therapeutics 28(1): 77-102.

14. McGuire JJ, P Hsieh, JK Coward, JR Bertino (1980) Enzymatic synthesis of folylpolyglutamates Characterization of the reaction and its products. Journal of Biological Chemistry 255(12): 5776-5788.

15. Widemann BC, PC Adamson (2006) Understanding and managing methotrexate nephrotoxicity. The oncologist 11(6): 694-703.

16. Allegra CJ, JC Drake, J Jolivet, BA Chabner (1985) Inhibition of phosphoribosylaminoimidazolecarboxamide transformylase by methotrexate and dihydrofolic acid polyglutamates. Proceedings of the National Academy of Sciences 82(15): 4881-4885.

17. Cetiner M, Göksel Sener, A Ozer Sehirli, Emel Ekşioğlu-Demiralp, Feriha Ercan, et al. (2005) Taurine protects against methotrexateinduced toxicity and inhibits leukocyte death. Toxicology and applied pharmacology 209(1): 39-50.

18. Olsen EA (1991) The pharmacology of methotrexate. Journal of the American Academy of Dermatology 25(2): 306-318.

19. Uzar E, Sahin O, Koyuncuoglu HR, Uz E, Bas O, et al. (2006) The activity of adenosine deaminase and the level of nitric oxide in spinal cord of methotrexate administered rats: protective effect of caffeic acid phenethyl ester. Toxicology 218(2-3): 125-133.

20. Fries JF, G Singh, L Lenert, DE Furst (1990) Aspirin, hydroxychloroquine, and hepatic enzyme abnormalities with methotrexate in rheumatoid arthritis. Arthritis \& Rheumatology 33(11): 1611-1619.

21. Vezmar S, Achim Becker, Udo Bode, Ulrich Jaehde (2003) Biochemical and clinical aspects of methotrexate neurotoxicity. Chemotherapy 49(1-2): 92-104.

22. Linnebank, $\mathrm{M}, \mathrm{H}$ Pels, $\mathrm{N}$ Kleczar, $\mathrm{S}$ Farmand, $\mathrm{K}$ Fliessbach, et al (2005) MTX-induced white matter changes are associated with polymorphisms of methionine metabolism. Neurology 64(5): 912-913.
23. Soliman AM, Fahmy SR, Abied SA (2015) Anti-neoplastic activities of sepia officinalis ink and coelatura aegyptiaca extracts against Ehrlich ascites carcinoma in Swiss albino mice. International journal of clinical and experimental pathology 8(4): 3543-3555.

24. Indap M, Radhika S, motiwale L, Rao KVK (2006) Quercetin: antitumor activity and pharmacological manipulations for increased therapeutic gains. Indian Journal of Pharmaceutical Sciences 68(4): 465-469.

25. Seelinger M, Popescu R, Giessrigl B, Jarukamjorn K, Unger C, et al. (2012) Methanol extract of the ethnopharmaceutical remedy Smilax spinosa exhibits anti-neoplastic activity. International journal of oncology 41(3): 1164-1172.

26. Raposo MFDJ, Morais AMMBD, Morais RMSCD (2015) Carotenoids from marine microalgae: A valuable natural source for the prevention of chronic diseases. Marine drugs 13(8): 5128-5155.

27. Chung YC, Chen SJ, Hsu CK, Chang CT, Chou ST (2005) Studies on the antioxidative activity of Graptopetalum paraguayense E Walther. Food Chemistry 91(3): 419-424.

28. Matusiewicz M, Kosieradzka I, Zuk M, Szopa J (2015) Effect of dose and administration period of seed cake of genetically modified and nonmodified flax on selected antioxidative activities in rats. International journal of molecular sciences 16(6): 14259-14275.

29. Teixeira ÉW, Negri G, Meira RM, Salatino A (2005) Plant origin of green propolis: bee behavior, plant anatomy and chemistry. Evidence-Based Complementary and Alternative Medicine 2(1): 85-92.

30. Moura SALD, Ferreira MAND, Andrade SP, Reis MLC, Noviello MDL, et al. (2009) Brazilian green propolis inhibits inflammatory angiogenesis in a murine sponge model. Evidence Based Complementary and Alternative Medicine 2011: 33.

31. Bankova V (2005) Chemical diversity of propolis and the problem of standardization. Journal of ethnopharmacology 100(1-2): 114-117.

32. Salatino A, Teixeira ÉW, Negri G (2005) Origin and chemical variation of Brazilian propolis. Evidence-Based Complementary and Alternative Medicine 2(1): 33-38.

33. Bankova V (2005) Recent trends and important developments in propolis research. Evidence-based complementary and alternative medicine 2(1): 29-32.

34. Hunter A (2006) Propolis, which bee product is that? Australian Pharmacist 25(6): 728-728.

35. Lotfy M (2006) Biological activity of bee propolis in health and disease. Asian Pac J Cancer Prev 7(1): 22-31

36. Gispert E, Cantillo E, Rivero A, Padrón M (2000) Actividad anticaries de una crema dental con propóleos Revista Cubana de Estomatología 37: 166-170.

37. Serkedjieva J, Manolova N, Bankova V (1997) Anti-influenza virus effect of some propolis constituents and their analogues (esters of substituted cinnamic acid). J Nat Prod 55: 294-302.

38. Ecsanu V, Prahoveanu E, Cricsan I, Cioca A (1981) The effect of aqueous propolis extract on experimental influenza virus infection in mice. Virolgie 32: 213-215.

39. Ito J, Chang FR, Wang HK, Park YK, Ikegaki M, et al. (2001) Anti-AIDS agents (1) Anti-HIV activity of moronic acid derivatives and the new melliferone-related triterpenoid isolated from Brazilian propolis. J Nat Prod 64: 1278-1281.

40. Mirzoeva O, Calder P (1996) The effect of propolis and its components on eicosanoid production during the inflammatory response. Prostaglandins, Leukotrienes and Essential Fatty Acids 55(6): 441449 . 
41. Kujumgiev A, Tsvetkova I, Serkedjieva Yu, Bankova V, Christov R, et al (1999) Antibacterial, antifungal and antiviral activity of propolis of different geographic origin. J Ethnopharmacol 64(3): 235-240.

42. Ota C, Unterkircher C, Fantinato V, Shimizu MT (2001) Antifungal activity of propolis on different species of Candida. Mycoses 44: 375378.

43. Higashi KO, De Castro SL (1995) Effect of different formulations of propolis on mice infected with Trypanosoma cruzi. J Ethnopharmacol 46: 55-58.

44. Araujo MAR, Libério SA, Guerra RNM, Ribeiro MNS, Nascimento FRF (2012) Mechanisms of action underlying the antiinflammatory and immunomodulatory effects of propolis: a brief review. Revista Brasileira de Farmacognosia 22(1): 208-219.

45. Song YS, Park E-H, Hur GM, Ryu YS, Kim YM, et al. (2002) Ethanol extract of propolis inhibits nitric oxide synthase gene expression and enzyme activity. Journal of Ethnopharmacology 80(2): 155-161.

46. Hämäläinen $\mathrm{M}$, Nieminen $\mathrm{R}$, Vuorela $\mathrm{P}$, Heinonen $\mathrm{M}$, Moilanen E (2007) Anti-inflammatory effects of flavonoids: genistein, kaempferol, quercetin, and daidzein inhibit STAT-1 and NF-kB activations, whereas flavone, isorhamnetin, naringenin, and pelargonidin inhibit only NF- $\mathrm{BB}$ activation along with their inhibitory effect on iNOS expression and NO production in activated macrophages. Mediators of inflammation 2007: 45673

47. Oršolić N, Šver L, Terzić S, Bašić I (2005) Peroral application of watersoluble derivative of propolis (WSDP) and its related polyphenolic compounds and their influence on immunological and antitumour activity. Veterinary Research Communications 29(7): 575-593.

48. Inoue K, Saito M, Kanai T, Kawata T, Shigematsu N, et al. (2008) Antitumor effects of water-soluble propolis on a mouse sarcoma cell line in vivo and in vitro. American Journal of Chinese Medicine 36(03): 625 634.

49. Bazo AP, Rodrigues MAM, Sforcin JM, De Camargo JLV, Ribeiro LR, et al. (2002) Protective action of propolis on the rat colon carcinogenesis. Teratogenesis, Carcinogenesis, and Mutagenesis 22(3):183-194.

50. Paredes-Guzman JF, Daugsch A, Park YK, Rhim JS, Li H, et al. (2007) Antiproliferation of human prostate cancer cells by ethanolic extracts of Brazilian propolis and its botanical origin. International Journal of Oncology 31: 601-606.

51. Awale S, Li F, Onozuka H, Esumi H, Tezuka Y, et al. (2008) Constituents of Brazilian red propolis and their preferential cytotoxic activity against human pancreatic PANC-1 cancer cell line in nutrient-deprived condition. Bioorganic \& Medicinal Chemistry 16(1):181-189.

52. Cogulu O, Biray C, Gunduz C, Karaca E, Aksoylar S, et al. (2009) Effects of Manisa propolis on telomerase activity in leukemia cells obtained from the bone marrow of leukemia patients. International Journal of Food Sciences and Nutrition 60(7): 601-605.

\section{ISSN: 2574-1241}

DOI: $10.26717 /$ BJSTR.2021.39.006258

Maha M Salem. Biomed J Sci \& Tech Res

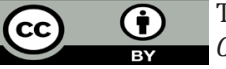

This work is licensed under Creative Commons Attribution 4.0 License

Submission Link: https://biomedres.us/submit-manuscript.php
53. Josipović P, Oršolić N (2008) Cytotoxicity of polyphenolic/flavonoid compounds in a leukaemia cell culture. Archives of Industrial Hygiene and Toxicology 59(4): 299-308.

54. Khan MS, Devaraj H, Devaraj N (2011) Chrysin abrogates early hepatocarcinogenesis and induces apoptosis in N-nitrosodiethylamineinduced preneoplastic nodules in rats. Toxicology and Applied Pharmacology 251(1): 85-94.

55. Pratsinis H, Kletsas D, Melliou E, Chinou I (2010) Antiproliferative activity of Greek propolis. Journal of Medicinal Food 13(2): 286-290.

56. Najafi MF, Vahedy F, Seyyedin M, Jomehzadeh HR, Bozary K (2007) Effect of the water extracts of propolis on stimulation and inhibition of different cells. Cytotechnology 54(1): 49-56.

57. Wang T, Chen L, Wu W, Long Y, Wang R (2008) Potential cytoprotection: antioxidant defence by caffeic acid phenethyl ester against free radical-induced damage of lipids, DNA, and proteins. Canadian Journal of Physiology and Pharmacology 86(5): 279-287.

58. Silva V, Genta G, Moller M, Masner M, Thomson L, et al. (2011) Antioxidant activity of Uruguayan propolis In vitro and cellular assays. Journal of Agricultural and Food Chemistry 59: 6430-6437.

59. Akao Y, Maruyama H, Matsumoto K, Ohguchi K, Nishizawa K, et al (2003) Cell growth inhibitory effect of cinnamic acid derivatives from propolis on human tumor cell lines. Biological and Pharmaceutical Bulletin 26(7): 1057-1059.

60. Fuliang HU, Hepburn HR, Hongzhuan X, Minli C, Dayad S, et al. (2005) Effects of Propolis on Blood Glucose, Blood Lipid, and Free Radicals in Rats with Diabetes Mellitus. Pharmacology Research 51: 147-152.

61. Eid HM, Vallerand D, Muhammad A, Durst T, Haddad PS, et al. (2010) Structural constraints and the importance of lipophilicity for the mitochondrial uncoupling activity of naturally occurring caffeic acid esters with potential for the treatment of insulin resistance. Biochemical Pharmacology 79(3): 444-454.

62. De Barros MP, Lemos M, Maistro EL, Leite MF, Sousa JPB, et al. (2008) Evaluation of antiulcer activity of the main phenolic acids found in Brazilian Green Propolis. Journal of Ethnopharmacology 120(3): 372 377.

63. Cole N, Sou PW, Ngo A, Tsang KH, Severino JA, et al. (2010) Topical 'Sydney' propolis protects against UV-radiation-induced inflammation, lipid peroxidation and immune suppression in mouse skin. International Archives of Allergy and Immunology 152(2):87-97.

64. Kudugunti SK, Vad NM, Whiteside AJ, Naik BU, Yusuf MA, et al. (2010) Biochemical mechanism of caffeic acid phenylethyl ester (CAPE) selective toxicity towards melanoma cell lines. Chemico-Biological Interactions 188(1): 1-14.

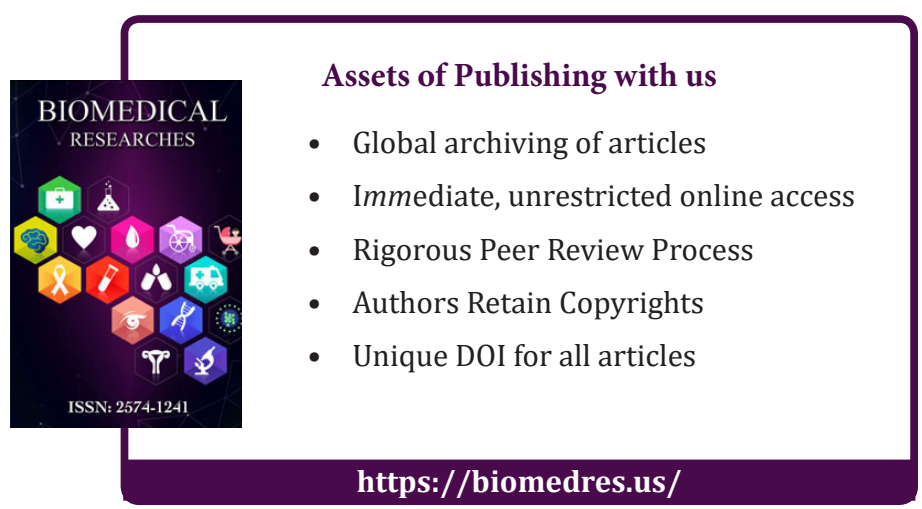

